Nevşehir Bilim ve Teknoloji Dergisi Cilt 3(2) 57-65 2014

DOI: 10.17100/nevbiltek.210934

URL: http://dx.doi.org/10.17100/nevbiltek.210934

\title{
X-Işını ile Işınlanmış Sesamia nonagrioides Lefebvre (Lepidoptera: Noctuidae) \\ Larva ve Pupalarında Deformasyon ve Ölüm Oranı Üzerine Araştırma
}

\author{
Hatice Avan Aksoy ${ }^{1, *}$, Cengiz Bahadıroğlu ${ }^{1}$ \\ ${ }^{1}$ Kahramanmaraş Sütçü İmam Üniversitesi, Fen-Edebiyat Fakültesi, Biyoloji Bölümü, Kahramanmaraş \\ Özet \\ Bu çalışmada X-ışını radyasyonun S. nonagrioides larva ve pupalarında deformasyon ve ölüm oranına etkileri incelenmiştir. \\ Larvalar farklı dozlarda (0-200 Gy) radyasyona maruz bırakıldıktan sonra deformasyon oranı kontrolde \%1.3 iken, en yüksek 150 \\ ve 200 Gy’de \%100 olmuştur. Ölüm oranı kontrolde \%6.2 ve 200 Gy’de \%99.3 olarak hesaplanmıştır. Işınlanan pupalar arasında \\ deformasyon oranı kontrolde \%2,2; 150 ve 200 Gy'de \%100; ölüm oranı ise sırası ile \%8.3, \%95.8 ve \%100 olmuştur. Ayrıca \\ pupalardan uçuşan erginler arasında deformasyon oranı kontrolde \%2,2 iken, 150 ve 200 Gy'de \%100 olarak gözlenmiştir. Böylece, \\ doz artışına bağlı olarak larva, pupa ve erginler arasında deformasyon ve ölüm oranın yükseldiği ve bununda sonraki gelişme \\ evrelerinde popülasyon düzeyinde azalmalara yol açacağı ihtimalini vermektedir.
}

Anahtar Kelimler: S. nonagrioides, X-1şını, Deformasyon, Ölüm oranı

\section{Investigate on the Rate of Deformation and Mortality in X-ray Irradiation Sesamia nonagrioides Lefebvre (Lepidoptera: Noctuidae) Larvae and Pupae}

\begin{abstract}
In this study, the effects of X-ray radiation were examined the rates of deformation and mortality of $S$. nonagrioides larvae and pupae. After exposure to radiation larvae at different doses (0-200 Gy), the rate of deformation was higher at 150 and $200 \mathrm{~Gy}$ (100\%) than control (1.3\%). Mortality was calculated 6.2\% at control and $99.3 \%$ at $200 \mathrm{~Gy}$. The rate of deformation at between irradiated pupae was $2.2 \%$ at control and $100 \%$ at 150 and $200 \mathrm{~Gy}$; rate of mortality $8.3 \%, 95.8 \%$ and $100 \%$ respectively. In addition, deformation was $2.2 \%$ in control, $100 \%$ at 150 and $200 \mathrm{~Gy}$ in between adult emerged from pupae. Thus, the rate of deformation and mortality rise in between larvae, pupae and adult on depending dose increases and provides the possibility to lead to depletion of this population in later stages of development.
\end{abstract}

Keywords: S. nonagrioides, X-ray, Deformation, Mortality

\footnotetext{
*e-mail: haticeavan@hotmail.com
} 


\section{Giriş}

Tarım ürünlerinin gerek yetiştirilme aşamasında gerekse depo edilerek saklanmasında zararlı böceklerden korumak amacıyla yoğun bir şekilde insektisit kullanımı tercih edilmektedir. Fazla kimyasal kullanımı ise; zararlılarla mücadelede başarılı sonuçlar verse de bazı böceklerin beslenme alışkanlıklarından dolayı neredeyse hiç etkide bulunmamakta ve bunun yanı sıra yararlı böcek faunasına, doğaya, üründe birikme yoluyla insanlara kadar zarar vermektedir [1, 2] Bu etkileri azaltmak amaçlı yapılan uygulamalar arasından farklı prensip ve tekniği ile radyasyon kullanımı öne çıkmaktadır.

Zararlı böcekleri kontrol altına almada radyasyon kullanımı birçok çevre (Uluslararası Atom Enerji Kurumu, ve Gıda Tarım Organizasyonu gibi) tarafından ucuz ve kolay elde edilebilirliği kabul görmektedir. $\mathrm{Bu}$ yöntem, erkek böceklerin kısırlaştırılıp yaban ortama salınarak çiftleşme rekabetine girmesi ve verimsiz yumurtalar oluşmasına neden olarak, populasyonun kontrol altında tutulması esasına dayanmaktadır [3, 4].

Radyasyon (X, gama ve UV gibi) canlı materyallerde moleküler bağların kırılmasına, iyonların ve serbest radikallerin ortaya çıkmasına neden olmaktadır. Serbest radikallerin oluşması moleküler bağların kırılmasında daha zararlı olup DNA'da direkt hasar oluşturarak özellikle germ hücrelerinde baskın öldürücü mutasyonlara yol açmaktadır. Bu kimyasal değişimler DNA üzerinde hasar meydana getirir ve böylece canlı hücrenin bölünmesini engelleyerek maruz kalan parazit, böcek, bakteri gibi organizmaların ve mantar sporları gibi yapıların kısırlaşmasına ve ölümüne neden olur Somatik hücreler özellikle mitoz bölünme geçiriyorsa zarar daha da çok olmaktadır. Genellikle hücre germ de olsa somatik de hasar doza bağlı olarak gelişir ve özellikle böceklerde bunlar gelişimlerinin ilerleyen evrelerinde tamir edilebilir [5, 6, 7]. Tamir mekanizmasının yeterli olmadığı durumlarda radyasyondan kaynaklanan mutasyonlar sonucu hem genotip hemde fenotip de anormallikler ortaya çıkabilmektedir.

Sesamia nonagrioides Lefebvre (Lepidoptera: Noctuidae) polifag bir tür olup, özellikle ülkemizde mısır zararlısı olarak bilinmektedir. Yılda 3-4 döl verebilen bu zararlı Doğu Akdeniz bölgesinde özellikle ikinci üründe yoğun ürün kayıplarına neden olarak ekonomik kayıplara yol açmaktadır. Zararlıyla mücadelede yoğun olarak kimyasal kullanılsa da böceğin beslenme alışkanlığından (endofitik) dolayı yetersiz kalmaktadır [8, 9, 10].

Bu çalışma X-ışını radyasyonun $S$. nonagrioides beşinci dönem larva ve beş günlük pupalarında deformasyon ve ölüm oranına etkilerini incelemek amacıyla gerçekleştirilmiştir.

\section{Materyal ve Metot}

\subsection{Test Böcekleri}

Çalışmada kullanılan larvalar 23.5-24 ${ }^{\circ} \mathrm{C}$ sıcaklık, \%65-70 orantılı nem ve 16: 8 (aydınlık: karanlık) aydınlatmalı iklim dolaplarında beşinci dönem oluncaya kadar taze mısır dane, yaprak ve püskülü ile beslenmiş ve 1 lt hacminde plastik kaplarda beşer adet olmak koşulu ile tutulmuştur. Pupalar ise; laboratuvarda çoğaltılan larvalar pupalaştıktan sonra kaplardan toplanarak çalışılmıştır. $S$. nonagrioides'in laboratuvarda çoğaltılmasında Koç ve Tüsüz [11]; Sertkaya ve Kornoşor [12] tarafından önerilen yöntemlerden faydalanılmıştır. 


\subsection{Böceklerin Işınlanması}

S. nonagrioides'in beşinci dönem larva ve beş günlük pupaları Gaziantep Üniversitesi Onkoloji Hastanesi'nde yüksek enerjili Lineer Accelerator (Elekta, 6 MV, Sinerji Platform) cihazında X radyasyonu (kontrol,50, 100, 150 ve 200 Gy) ile 1şınlanmıştır. Her bir deney serisinde toplamda 160 adet (4 x 40 adet) larva ve 120 adet (4 x 30 adet) pupa ışınlanmıştır. Hedeflenen dozlar radyokromik film dozimetreleri (Harwell, Gammachrome YR, Perspex Dosimeter, Batch 62, Range 0.1-3 kGy) kullanılarak görüntülenmiştir.

Radyasyon çalışmalarında böceklerin farklı evrelerinde etkili sonuçlar elde etmek için Hallman [13] tarafından da önerildiği gibi tam başkalaşım gösteren böceklerde erken dönem larvaların tamir mekanizmalarının oluşan hasarları tolere edebilmesinden dolayı son dönem larvalar tercih edilmektedir. Pupa evresi; kısır ergin elde edebilmek tercih edilmiş ve S. nonagrioides'in pupal evresinin (ortalama 11.8 gün) yaklaşık yarısı olan 5. gün hedef alınmıştır.

\subsection{Verilerin Değerlendirilmesi}

Elde edilen veriler arasındaki farkları Varyans Analizi (One-Way ANOVA), uygulamalar arasında farklar olduğu durumlarda ise Tukey's ya da Tukey's stundized test metotlarından yararlanılmıştır (SPSS 15.0, 2006). Ortalamalar arasındaki fark 0.05 olasılık seviyesinde F değerinden büyük olduğu takdirde önemli kabul edilmiştir.

\section{Bulgular}

Bu çalışmada 0 (kontrol), 50, 100, 150 ve 200 Gy dozlarda X-1şınına maruz bırakılmış 5. dönem S. nonagrioides larvalarında deformasyon ve ölüm oranı araştırılmış ve elde edilen değerler Tablo 1 'de verilmiştir.

Tablo 1. Işınlanmış 5. Dönem larvalarda deformasyon ve ölüm oranı

\begin{tabular}{|c|c|c|c|c|c|}
\hline \multirow{2}{*}{$\begin{array}{l}\text { Doz } \\
\text { (Gy) }\end{array}$} & \multirow[t]{2}{*}{$\mathbf{n}$} & \multicolumn{2}{|c|}{ Deformasyon oranı } & \multicolumn{2}{|c|}{ Ölüm oranı } \\
\hline & & Toplam & \% değeri & Toplam & \% değeri \\
\hline 0 (kontrol) & 160 & $1 \mathrm{a}$ & $1.3 \pm 1.3 \mathrm{a}$ & $10 \mathrm{a}$ & $6.2 \pm 2.3 \mathrm{a}$ \\
\hline 50 & 160 & $6 \mathrm{~b}$ & $33.3 \pm 4.5 b$ & $142 b$ & $88.7 \pm 1.9 \mathrm{~b}$ \\
\hline 100 & 160 & $11 \mathrm{c}$ & $73.3 \pm 12.4 \mathrm{c}$ & $145 b$ & $90.6 \pm 3.7 b$ \\
\hline 150 & 160 & $3 d$ & $100 \pm 0.0 \mathrm{~d}$ & $157 \mathrm{c}$ & $98.1 \pm 2.5 c$ \\
\hline 200 & 160 & $1 \mathrm{~d}$ & $100 \pm 0.0 \mathrm{~d}$ & $159 c$ & $99.3 \pm 1.8 \mathrm{c}$ \\
\hline
\end{tabular}

Aynı harflerle gösterilen değerlerin ortalama varyans analizi ve Tukey testine göre \%5 düzeyinde istatiksel olarak önemli değildir.

Deformasyon oranı ise kontrolde \%1.3, 50 Gy’de \%33. 3, 100 Gy'de \%73.3, 150 ve 200 Gy'de ise; \%100 olarak saptanmıştır. Grafik1'de ışınlanmış her bir deney gurubundan oluşan normal ve deformasyonlu pupaların yüzde değerleri verilmiştir. 
Avan-Aksoy H., Bahadıroğlu C.

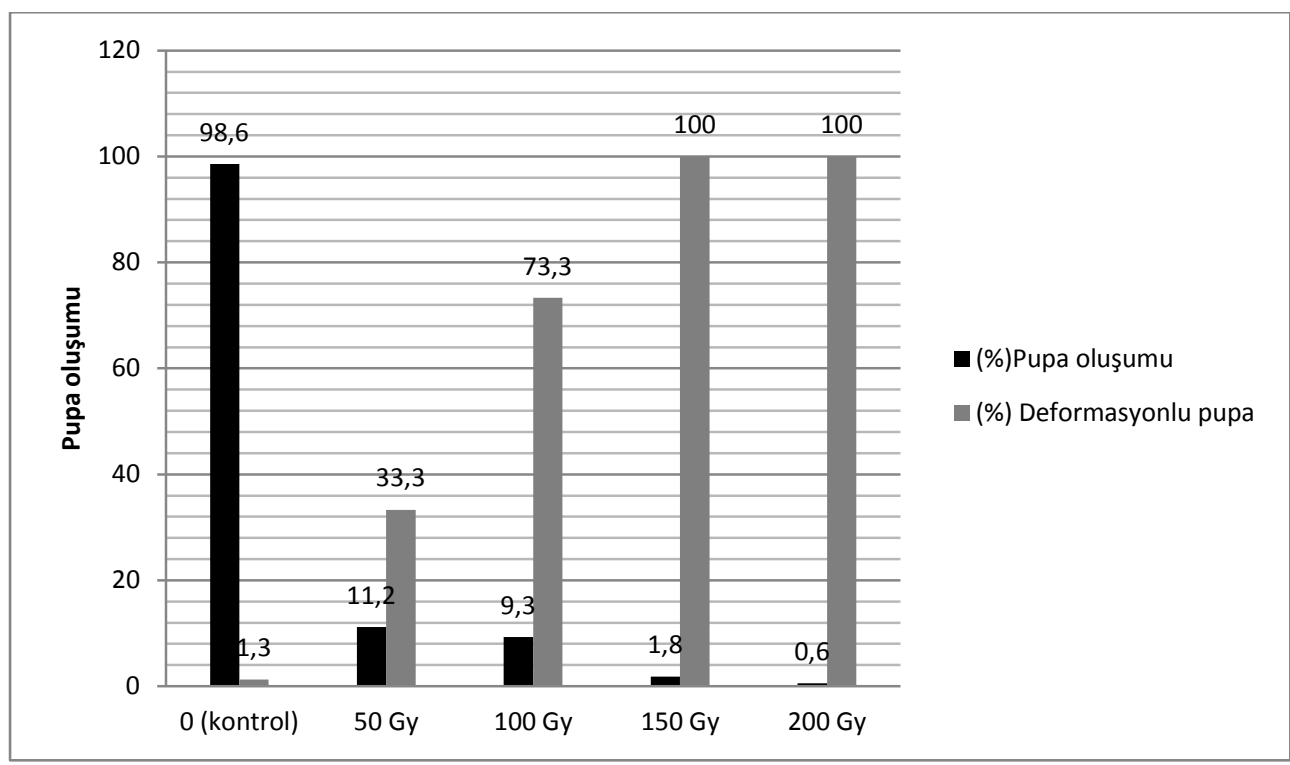

Grafik 1. Işınlanmış S. nonagrioides normal ve deformasyonlu pupaların oranı.

Doz artışına bağlı olarak normal pupaların oranı azalırken, deformasyon oranının ise arttı̆̆ belirlenmiştir. Radyasyonun pupaya giren larvalarda morfolojik olarak sağlıklı pupalara göre pupa evresine tam geçemedikleri, geçenlerin ise; Şekil 1'de görüldüğü gibi yapılarında, boyutlarında ve renklerinde kontroldekilere göre anormallikler olduğu gözlenmiştir.

Işınlanmış larvalarda ölüm oranı kontrolde \%6.2, 50 Gy’de \%88.7, 100 Gy’de \%90.6, 150 Gy’de \%98.1 ve 200 Gy’de \%99.3 olarak hesaplanmıştır. Ayrıca; ölüm oranının da doza bağlı olarak artış gösterdiği saptanmıştır.
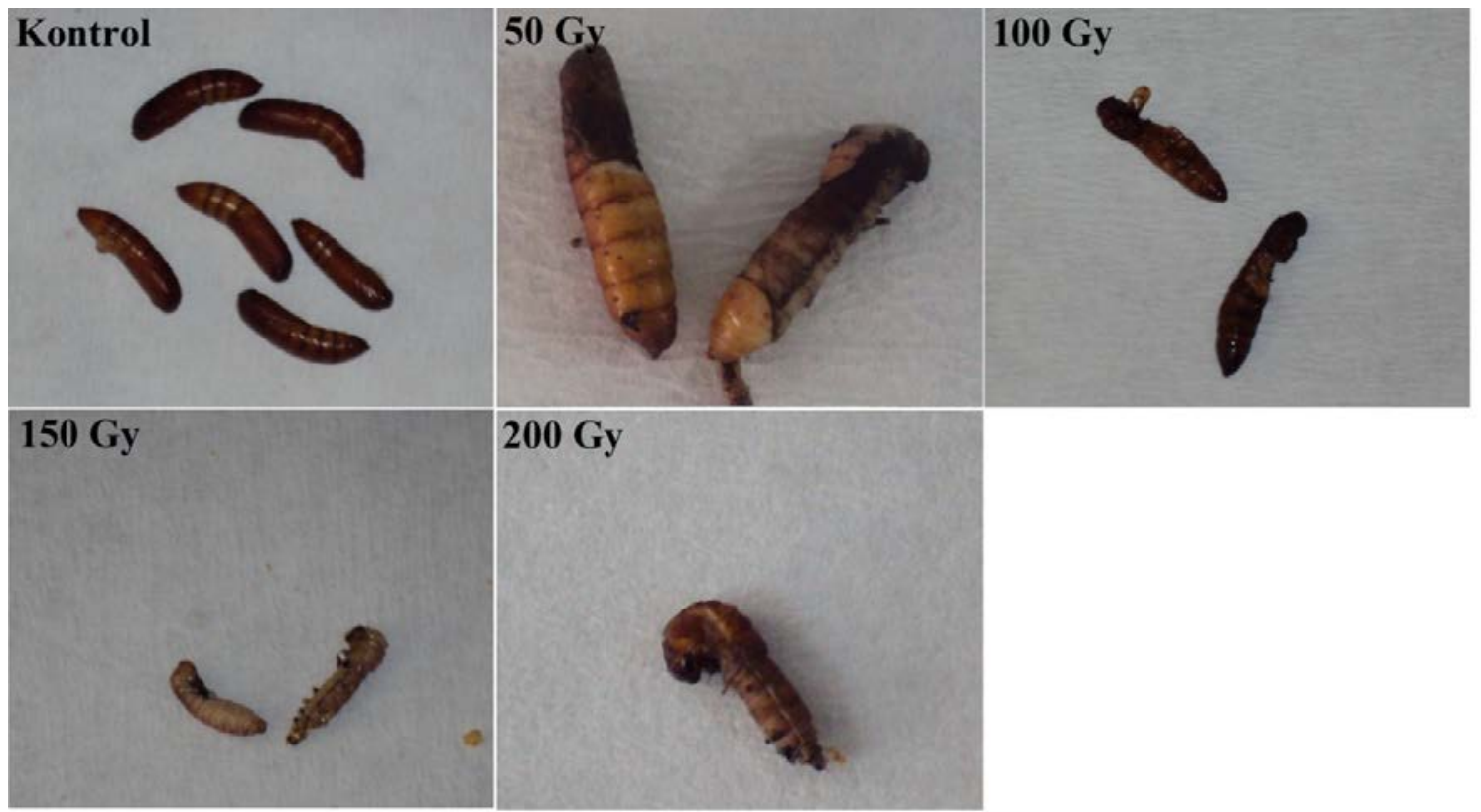

Şekil 1. Işınlanmış larvalardan oluşan deformasyonlu pupalar.

Pupa evresinde farklı dozlarda (0-200 Gy) radyasyon kullanımı sonucu belirlenen deformasyon ve ölüm oranı Tablo 2'de verilmiştir. Ölüm oranı kontrolde \%8.3 iken, 50 Gy’de \%63.3, 100 Gy’de 
\%90.8, 150 Gy’de \%95.8 ve 200 Gy’de ise; bu oran \%100’e ulaşmış ve bu deney gurubunda ergin çı1kş1 gözlenmemiştir.

Tablo 2. Farklı dozlarda ışınlanmış S. nonagrioides pupalarında deformasyon ve ölüm oranı

\begin{tabular}{|c|c|c|c|c|c|}
\hline \multirow{2}{*}{$\begin{array}{l}\text { Doz } \\
\text { (Gy) }\end{array}$} & \multirow[t]{2}{*}{$\mathbf{n}$} & \multicolumn{2}{|c|}{ Deformasyon oranı } & \multicolumn{2}{|c|}{ Ölüm oranı } \\
\hline & & Toplam & $\%$ değeri & Toplam & \% değeri \\
\hline 0 (kontrol) & 120 & $2 \mathrm{a}$ & $2.2 \pm 0.06 \mathrm{a}$ & $10 \mathrm{a}$ & $8.3 \pm 1.88 \mathrm{a}$ \\
\hline 50 & 120 & $36 \mathrm{~b}$ & $81.8 \pm 8.5 b$ & $76 \mathrm{~b}$ & $63.3 \pm 2.27 \mathrm{~b}$ \\
\hline 100 & 120 & $5.5 \mathrm{c}$ & $50 \pm 2.7 \mathrm{c}$ & $109 \mathrm{c}$ & $90.8 \pm 9.2 \mathrm{c}$ \\
\hline 150 & 120 & $5 \mathrm{c}$ & $100 \pm 0.0 \mathrm{~d}$ & $115 \mathrm{~d}$ & $95.8 \pm 7.51 \mathrm{~d}$ \\
\hline 200 & 120 & $0 \mathrm{~d}$ & $0.0 \pm 0.0 \mathrm{e}$ & $120 \mathrm{e}$ & $100 \pm 0.0 \mathrm{e}$ \\
\hline
\end{tabular}

Aynı harflerle gösterilen değerlerin ortalama varyans analizi ve Tukey testine göre $\% 5$ düzeyinde istatiksel olarak önemli değildir.

Işınlanmış pupalardan çıkan erginlerin kanat ve antenlerinde şekilsel bozukluklar, bedensel olarak zayıflık ve hareketsizlik gibi anormallikler (deformasyon) gözlenmiştir. Erginlerde gözlenen deformasyon oranı kontrolde \%2.2 iken, 50 Gy’de \%81.8, 100 Gy’de \%50, 150 ve 200 Gy’de \%100 olarak gözlenmiştir. Deformasyonlu kelebeklerin görüntüsü Şekil 2'de gösterilmiştir.
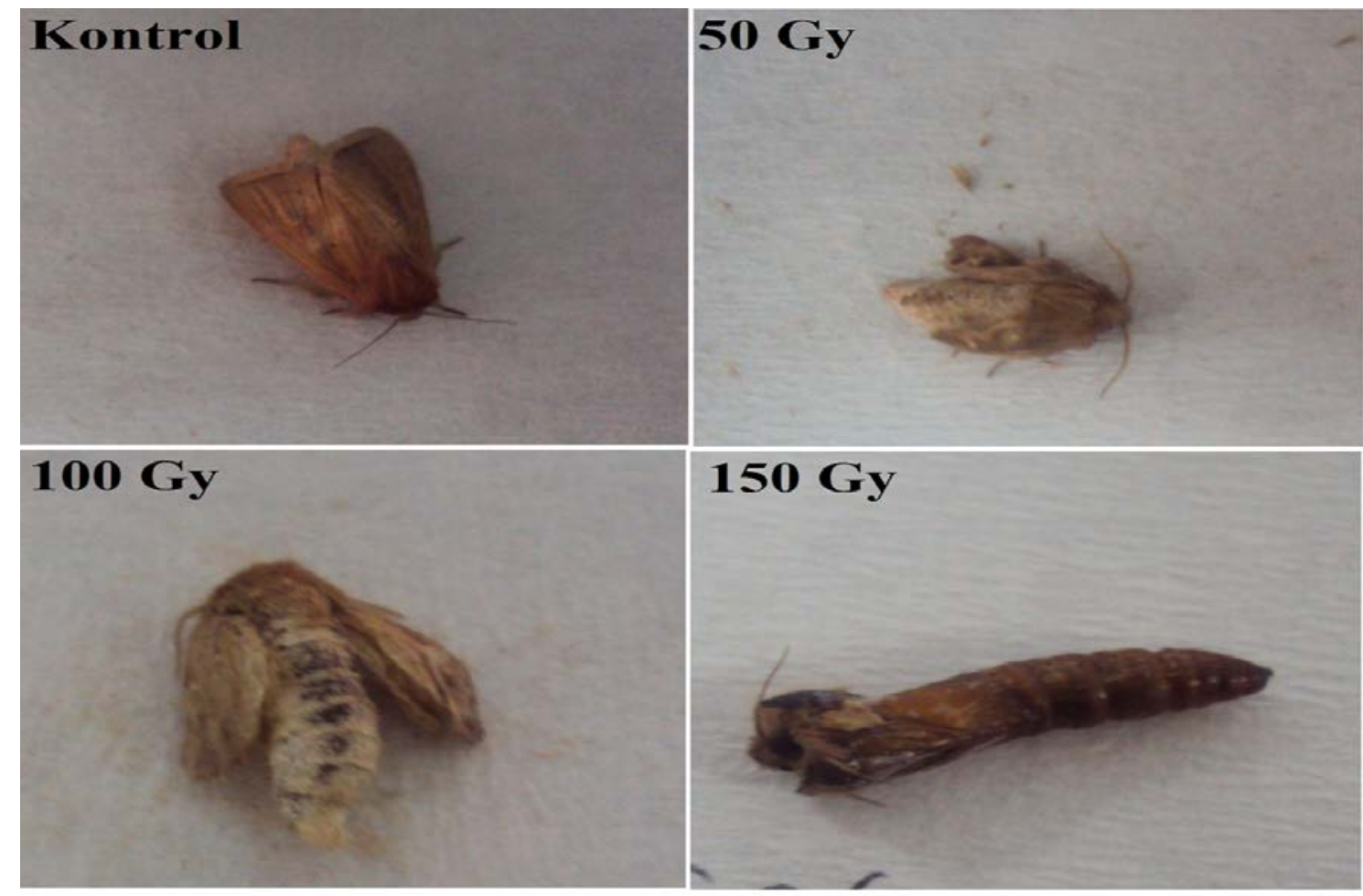

Şekil 2. Iş̧ılanmış pupalardan çıkan deformasyonlu erginler

\section{Tartışma ve Sonuç}

Çalışmamızda X-ışının farklı dozlarının (0-200 Gy) S. nonagriodes beşinci dönem larva ve beş günlük pupalarında deformasyon ve ölüm oranı üzerine etkileri incelenmiştir. Larvalarda ölüm oranı doz 
artışına bağlı olarak artış göstermiş ve bu oran 200 Gy'de \%99.3'ye ulaşmıştır. Zolfagharieh [14], 0.09 kGy gama radyasyonu ile ışınlandığı Oryzaephilus surinamensis L. (Coleoptera: Silvanidae) larvalarının 7 gün içerisinde \%100'ünün öldüğünü belirtmiştir. Hosseinzadeh ve ark. [15] ise; 0-400 Gy arasında ışınlanan $O$. surinamensis larvalarında ölüm oranının doz artışına bağlı olarak yükseldiğini, her bir evreden sonra özellikle larvaların büyüme indeksinin önemli oranda azaldığı, ergin oluşum süresinin yavaşladığını, O. surinamnesis'in pupa ve erginlerini kontrol altına almak için; 600 ve 700 Gy ışın kullanılmasının daha uygun olacağını belirtmişlerdir. Başka bir çalışmada 250 Gy radyasyona maruz bırakıldığında, Ephestia kuehniella L. (Lepidoptera: Pyralidae)'nın son dönem larvalarında tamamen öldürücü etkiye sahip olduğu saptanmıştır [16]. Plodia interpunctella (Hubner) (Lepidoptera: Pyralidae)'nın dördüncü dönem larvaları üzerine gama radyasyonunun etkilerini belirlemek amacıyla yürütülmüş başka bir çalışmada, larvalar 300-900 Gy arasındaki dozlarda 1şınlanmıştır. Doz artışına bağlı olarak besin tüketimi ve larval ağılıklarında önemli derecede azalmaların olduğu, ışınlanmış larvaların pupaya girmesi ve pupalardan ergin bireylerin oluşumu tamamen engellendiği ve aynı zamanda; 450 Gy ve üzeri dozlarda ölüm oranının \%100'e ulaştığı belirlenmiştir [17].

Işınlanmış S. nonagrioides larvaları pupaya girdiklerinde meydana gelen deformasyonların doz artışına bağlı olarak arttı̆g 1 ve kontrolde \%1.3 iken, 200 Gy'de bu oranın \%100 olduğu saptanmıştır. Faruki ve ark. [18] tarafindan ultraviole radyasyonun Alphitobius diaperinus (Panzer) (Coleoptera: Tenebrionidae)'un pupaya giren larvalarda deformasyonlara neden olduğu belirtilmiştir. Başka bir çalışmada gama radyasyonun Agrotis ipsilon (Hufn.) (Lepidoptera: Noctuidae)'nun larvalarında deformasyon oranının doz artışına bağlı olarak yükselttiği belirlenmiştir [19].

Farklı dozlarda 1şınlanmış pupalarda ölüm oranı doza bağlı olarak artış göstermiş ve $200 \mathrm{~Gy}$ pupaların tamamının ölmesine neden olmuştur. Aldyrhim ve Adam [20], farklı dozda gama radyasyonuyla ışınladıkları Sitophilus granarius L. (Coleoptera: Curcillionidae)'nın pupalarının yumurta ve larva evresine göre çok etkilenmese de doz artışına bağlı olarak ölüm oranının yükseldiğini kaydetmişlerdir. Farklı bir çalışmada gama radyasyonunun 150 Gy’i Tribolum castaneum (Herbst.) (Coleoptera: Tenebrionidae)’un 1-2 günlük yumurtaların açılmasını, 100 Gy’i 15 günlük larvalardan sonuçta ergin çıkışını, 700 Gy 5 günlük pupalardan ergin çıkışını, 200 Gy radyasyon dozunun ise erginlerde \%100 öldürücü etkiye sahip olması için yeterli olduğu, larva ve pupalardan ergin çıkışının doz artışına bağlı olarak azaldığı, 700 Gy'in $T$. castaneum'un populasyonunu kontrol altına almada yeterli olabileceği kaydedilmiştir [21].

Işınlanmış pupalardan çıkan erginlerde ise; deformasyon oranı kontrolde \%2.2 iken 150 Gy’de \%100 olmuş ve 200 Gy'de ergin çıkışı gözlenmemiştir. Salem ve ark. [19]'na göre farklı dozda gama radyasyonu uygulanan A. ipsilon pupalarından çıkan erginlerde şekil bozuklukları doza bağlı olarak yükselmiştir. Başka bir çalışmada gama radyasyonun Teia anartoides (Lepidoptera: Lymantriidae) pupalarından çıkan erginlerde kanat anormalliklerine neden olduğu kaydedilmiştir [22]. Helicoverpa armigera (Hübner)'nın pupalarının farklı dozda gama radyasyonuyla ışınlandığı bir çalışmada ise; doz artışına bağlı olarak pupalardan uçuşan erginlerde deformasyon oranının artış gösterdiği bildirilmiştir [23]. Güney Afrika'da domates zararlısı olarak bilinen Tuta absoluta (Lep.: Gelechiidae) X-ışınına tutulmuş ve radyasyon dozunun artışına paralel olarak erkek ve dişi pupalardan ergin çıkışlarında azalmaların olduğu, 350 Gy ve üzeri dozlarının ise; morfolojik deformasyonlara yol açtığı 
kaydedilmiş̧ir. Ayrıca; radyasyona maruz kalan erginler (dişi ve erkek) radyasyona tutulmayan erkek ve dişilerle çaprazlanarak kısırlığın kalıtımı incelenmiş, 200 ve 250 Gy dozlarının erkeklerde, 200 Gy dozun ise; dişilerde kısırllğa neden olduğu belirlenmiş̧tir [24].

Dünya genelinde radyasyon kullanımı, kısırlaştırılmış erkek böceklerin yaban populasyonda çiftleşme rekabetine bırakılması, depo zararlılarına karşı ve fitosanitari (bitki koruma) gibi uygulamalarla hızla kabul görürken, bu gibi çalışmaların ülkemizde eksikliği de ortaya çıkmaktadır. Özellikle endofitik beslenme alışkanlığı olan zararlılara karşı böyle bir yöntemin geliştirilmesi, kimyasalların neden olduğu risklerin azaltılmasına ve ürünlerde ise; kalite ve verimin artmasına olanak sağlayacaktır. Çalışmada sonuç olarak; S. nongrioides larva ve pupaları farklı dozlarda (0-200 Gy) X-1şını radyasyonuna maruz bırakıldığında, her iki gelişme evresinde deformasyon ve ölüm oranının doz artışına bağlı olarak yükseldiği saptanmıştır. Özellikle ışınlanan pupalardan çıkan erginlerin kanatlarında meydana gelen şekilsel bozukluklar, kelebeklerin beslenmek ve çiftleşmek için uçuş rekabetinde başarısızlığa yol açarak yumurta veriminin azalmasına ve bu uygulama pratiğe aktarıldığında zararlı populasyonun kontrol altına alınmasına katkı sağlayacağını düşünmekteyiz.

\section{Kaynaklar}

[1] Konak C., "Planting of Maize At Different Times To Reduce Borer Damage in Eagen Region" Proceedings of a Symposium on Corn Borers And Control Measures 1-3 November, pp.21-24, Antalya, 1988

[2] Şimşek N., Güllü M., “Akdeniz Bölgesi’nde Mısırda Zarar Yapan Mısır Koçankurdu (Sesamia nonagrioides Lef.) (Lepidoptera: Noctuidae) ve Misırkurdu (Ostrinia nubilalis Hbn.) (Lepidoptera: Pyralidae)’nun Mücadelesine Esas Olabilecek Biyolojik Kriterlerin Araştırılması" Türkiye II. Entomoloji Kongresi Bildirileri 28-31 Ocak, pp. 501- 512, Adana, 1992

[3] Follett P.A., Neven L.G., "Current trends in quarantine entomology” Annu. Rev. Entomol., 51, 359-385, 2006

[4] Heather N.W., Hallman G.J., "Pest management and phytosanitary trade barriers" CABI International, Wallingford, Oxfordshire, United Kingdom, 2008

[5] Brower J.H., Tilton E.W., "The potential of Irradiation as Commodities in: Proceedings: Radiation Disinfestation of Food an Agricultural Products Conference” Edited by Moy J.H., Hawaii Institute of Tropical Agricultural and Human Research, University of Hawaii, p. 75-86, 1983

[6] Lapidot M., Saveanu S., Padova R., Ross I. 1991. Insect Disinfestation by Irradiation. Insect Disinfestation of Food and Agricultural Products by Irradiation. Proceedings IAEA, Vienna, 103 pp.

[7] Ahmed M., "Disinfestation of stored grain, pulses, dried fruits and nuts, and other dried foods in: Food Irradiation Principles and Applications” Edited by Molins R., Wiley, New York, p. 77112, 2001

[8] Cerit İ., Güllü M., Sarıhan H., Kanat A. D., Türkay M. A., Uçak A. B., "Mısırkurdu (Ostrinia nubilalis Hübner) (Lepidoptera: Crambidae) ve Mısır Koçankurdu (Sesamia nonagrioides 
Lefebvre) (Lepidoptera: Noctuidae) 'na Dayanıklı Transgenik Mısır Çeşidi Pioneer 33P67 (MON 810) Bt’ nin Alan Denemesi” Projesi sonuç raporu, Adana, 2006

[9] Öztemiz S., Güllü M., Özdemir F., Fidan H., Bülbül F., “Akdeniz Bölgesinde Mısırda Entegre Mücadele Arastırma, Uygulama ve Eğitim Çalısmaları Üzerine Arastırmalar” KSÜ Fen ve Mühendislik Dergisi, 11(2): 81-91,2008

[10] Özcan S., “Modern Dünyanın Vazgeçilmez Bitkisi Mısır: Genetiği Değiştirilmiş (Transgenik) Mısırın Tarımsal Üretime Katkısı” Türk Bilimsel Derlemeler Dergisi, 2(2), 01-34,2009

[11] Koç N., Tüsüz M.A., "Mısır Koçan Kurdu (Sesamia nonagrioides Lef., Sesamia cretica Led. Lepitoptera:Noctuidae)'nun Laboratuvarda Kitle Üretimi Üzerine Araştırmalar” Akdeniz Tarımsal Araştırma Enstitüsü Müdürlüğü, Yayın No: 17. 27s, Antalya, 1993

[12] Sertkaya E., Kornoşor S.,"Yumurta parazitoiti, Telenomus busseolae (Gahan) (Hym., Scelionidae)'nin Sesamia nonagrioides Lef. (Lep., Noctuidae) yumurtalannda bazı biyolojik özellikleri” Türk. Entomol. Derg., 27 (3), 231-239, 2003

[13] Hallman G.J., “ Ionizing Radiation Quarantine Treatments” An. Soc. Entomol. Brasil, 27 (3), 313-323, 1998

[14] Zolfagharieh H.R., "Irradiation to control Plodia interpunctella and Oryzaphillus surinamensis in pistacios and dates in: Proceeding of a final research coordination meeting organized” by the joint FAO/IAEA Division of Nuclear Techniques in Food and Agriculture, Vienna, Austria, p. 101-109, 2002

[15] Hosseinzadeh A., Shayesteh N., Olfagharieh H.R., Babaei M., Zareshahi H., Mostafavi H.A. Fatollahi H., "Gamma radiation sensitivity of different stages of saw-toothed grain beetle Oryzaphilus surinamensis L. (Coleoptera: Silvanidae)” Journal of Plant Protection Research, 50(3), 250-255, 2010

[16] Ayvaz A., Tuncbilek A.S., "Effects of gamma radiation on life stages of the Mediterranean flour moth Ephestia kuhniella Zeller (Lepidoptera: Pyralidae)” J. Pestic. Sci., 79, 215-222,2006

[17] Azelmat K., Sayah F., Mouhib M., Ghailani N., Elgarrouj D., "Effects of gamma irradiation on forth-instar Plodia interpunctella (Hubner) (Lepidoptera: Pyralidae)” Journal of Stored Product Research, 41, 423-431, 2005

[18] Faruki S.I., Das D.R., Khatun S., "Effects of UV-radiation on the larvae lesser mealworm, Alphitobius diaperinus (Panzer) (Coleoptera: Tenebrionidae) and their progeny” Journal of Biological Sciences, 5(4), 444-448, 2005

[19] Salem H.M., Fouda M.A., Abas A.A., Ali W.M., Gabarty A., "Effects of gama irradiation on the development and reproduction of the greasy cutworm, Agrotis ipsilon (Hufn.)” Journal of Radiation Research and Applied Sciences,7(1), 110-115, 2014

[20] Aldryhim Y.N., Adam E.E., "Efficacy of gamma irradiation against Sitophilus granaries (Coleoptera: Curculionidae)” J. Stored Product Res., 35 (3), 225-232, 1999

[21] Hosseinzadeh A., Shayesteh N., Zolfagharieh H.R., Bernousi I., Babaei M., Zareshahi H., Ahari M.H., Fatollahi H., "Effect of gamma radiation on different stages of Indian meal moth Plodia interpunctella Hübner (Lepidoptera: Pyralidae)” African Journal of Biotechnology, 10(20), 4259-4264, 2011 
[22] Suckling D.M., Pedley R., Wee S.L., "Pupal age affects efficacy of irradiation on painted apple moth Teia anartoudes” New Zealand Plant Protection, 57,166-170, 2004

[23] Pransopon P., Sutantawong M., Hormchan P., Wongpiyasatid A., "Effects of gamma radiation on mature pupae of the cotton bollworm, Helicoverpa armigera (Hubner) and their F1 progeny” Kasetsart J. (Nat. Sci.), 34: 401-407, 2000

[24] Cagnotti C.L., Viscarret M.M., Riquelma M.B., Botto, E.N. Carabajal LZ., Segura D. F., López S.N., "Effects of X-rays on Tuta absoluta for Use in Inherited Sterility Programmes” J. Pest. Sci., 85(4): 413-421, 2012 